\title{
The LBO-SBO Relationship
}

\author{
Keegan Parker Brockman \\ University of Florida
}

Faculty mentor: James Parrino, Warrington College of Business

\begin{abstract}
Since the beginning of the private equity industry in the 1980s, it has evolved and adopted new strategies and methods for generating returns to investors. As the industry grew, deals became harder to find as the buyer market grew immensely and what deals remained appeared picked over. Enter the secondary buyout (SBO). This strategy involves one financial sponsor buying a portfolio company from another financial sponsor. This thesis attempts to fill a gap in the field of research in two ways. First, this thesis analyzes the difference in value creation using a longitudinal and matched-sample approach. This approach is unique in that it will only analyze data for which information on the SBO, the preceding LBO, and the following exit are all available. Second, this thesis looks specifically at the relationship between LBOs and SBOs in an attempt to provide a practical application of the analysis. Additionally, most studies stray away from performing analysis on the U.S. market due to the limited data availability, but this approach ignores one of the largest private equity markets in existence. This thesis will look solely at U.S. buyouts. The findings show no significant difference in the relative change in enterprise value from acquisition to exit for LBOs or SBOs. Further, there is a statistically significant negative relationship between the holding period and annualized change in EV for both LBOs and SBOs. Finally, while the results were not significant, there is a slight negative relationship between the EV change of LBOs to the EV change of SBOs.

Keywords: Private Equity, Leveraged Buyout, Secondary Buyout
\end{abstract}

\section{Introduction}

Since the private equity (PE) industry sprouted-up in the 1980s as a byproduct of the junk bond vogue, the industry has evolved immensely to create and adopt new products and deal structures with the hope of maintaining or boosting fund performance. One of these developments was the creation of the now infamous secondary buyout (SBO). Simply put, SBOs are characterized by the buying and selling of portfolio companies between financial sponsors (as opposed to a sale to a strategic buyer or completing an IPO listing). SBOs, however, have received a healthy level of skepticism as to the merits of the transaction structure and whether fund managers should even consider the type of deal. Nonetheless, over the past couple of decades, the prevalence of SBO transactions has grown tremendously. Specifically, from 2010 to 2018, SBOs as a percentage of PE-backed exits grew from 36\% to 48\% (Wilder, 2018). Should 
this rapid growth be viewed in a positive light, or are SBOs a fad to be avoided? This thesis attempts to answer this question by analyzing the relationship between the transactions.

While the topic has been researched heavily, this paper is unique in that it focuses on the relationship between LBOs and SBOs. Previous studies tend to analyze returns or operational performance, but do not keep their data sets of LBOs and SBOs consistent by only including companies that have both LBO and SBO data available. Through only including companies that have both LBO and SBO transaction data available, the type of analysis that is possible is widened. Ultimately, through examining for a relationship between LBOs and SBOs, our current understanding of SBOs and their merit as a PE strategy should be expanded.

This relationship is analyzed through an examination of annualized enterprise value (EV) change. First, a test was run on the cross-sectional data to find if the mean of LBO EV change is significantly different from that of SBOs. Following, the same exact hypothesis test on a matched sample of LBO and SBO EV change was completed (the matched sample is described in more detail in the "Methodology" section of this paper). Third, whether a relationship exists between the EV change a company experiences and the holding period of that company by a PE fund was tested. This test was performed for LBOs, SBOs, and the matched sample. Finally, a direct relationship between the EV change of LBOs and SBOs was tested.

\section{Literature Review}

The first significant piece of research on secondary buyouts examined is "A Note on Secondary Buyouts-Creating Value or Recycling Capital," by Kitzmann and Schiereck. The authors examine whether SBOs create wealth, or if SBOs are a second-best alternative when other exit methods are unavailable. To answer this question, the researchers hypothesized that the four most common exit methods should be ranked in desirability as follows: IPO, trade sale, $\mathrm{SBO}$, and $\mathrm{MBO}$. Exit multiples were used to test whether this ranking was appropriate. A high exit multiple can be interpreted as the buyer attaching high value to the portfolio company and was, therefore, willing to pay a high price, making the transaction a value adding one. As a condition of this analysis, only comparable companies could be compared to one another due to a difference in industry average multiples that could otherwise create the appearance of significant results. Though the researchers acknowledge the results were "not unequivocal," they note they 
found no significant difference and thus SBOs should not be thought of as being a less profitable exit method.

In 2012, Yingdi Wang set out to study the economic logic and pricing of SBOs by investigating three potential reasons for their popularity: efficiency gains, liquidity-based market, timing, and collusion. Wang hypothesized that given the involved portfolio company in an SBO has already been "tuned-up" by the previous financial sponsor using typical PE strategy (high leverage, high-performance pay, better governance, etc.), the typical drivers in PE cannot explain SBO success. Consequently, the increasing volume of SBOs must mean that either the initial buyout failed, or that secondary buyouts have an alternative set of reasons driving them than the ones that drive the primary LBO market. In answering whether efficiency gains motivate SBOs, Wang found that while absolute profits increase, profitability dropped after an SBO, a mixed result. Conversely, the liquidity-based market timing hypothesis proved highly convincing. Wang found that firms are more likely to exit through an SBO when equity markets are cold, debt markets are hot, and the firm was pressured to exit their investment. As for the last question examined, whether collusion (PE firms choosing to trade with each other over other players in the market for non-economic reasons) plays a role in the popularity of SBOs, Wang discovered no significant trend.

In his paper "Secondary Buyouts: Operating Performance and Investment Determinants," Bonini makes the distinction that to determine whether an SBO sponsor can generate a change in performance similar to that of the first owner, it was necessary to track the same company throughout both buyouts. In other words, Bonini adopts a panel analysis or longitudinal approach. Contrasting the earlier studies mentioned, Bonini found SBOs, when they are compared to the LBO directly preceding, do not generate incremental operating performance and efficiency gains at the same level. Bonini found SBOs to exhibit evidence of higher leverage than the comparable primary buyout. Ultimately, lackluster operational improvements lead to relatively lower returns to $\mathrm{PE}$ investors. Thus, operational improvements cannot be the primary driver of SBO transactions, and other forces must be driving the strategy popularity. With this in mind, the author contemplated collusion as a possible answer to why SBOs multiplied in popularity, and while the idea has some theoretical backing, the author admittedly lacked support for this hypothesis. Lastly, Bonini searched for alternative drivers of SBOs and found that favorable credit market conditions and a PE fund's reputation at the least partially drive SBO 
volume. The approach taken in this thesis is most similar to Bonini's; however, this thesis focuses on U.S. data and uses enterprise value (EV) as a proxy for defining underlying asset (operational) improvement.

This final article examines questions very similar to those in previous literature; however, authors Plagborg-Moller and Holm focus on operating performance post-Global Financial Crisis and how that operational performance affects the decision to exit via IPO or SBO. The first hypothesis tested asserts that the better a portfolio company's operating performance at the time of exit, the more likely the investor will exit via IPO. The second hypothesis states that operating performance was an even more significant determinant post-Global Financial Crisis. Much like previous literature, the researchers focused on European data and collected the information from several databases. After analyzing the data, the authors found evidence that operating performance was an even more important determinant of PE exit channel after the Global Financial Crisis. While this study did not tackle the question as to whether returns of SBOs are significantly different from that of primary buyouts, their finding that greater operational improvements lead to a higher likelihood of IPO implies that PE fund managers see SBOs as a less preferable or less profitable exit option.

\section{Data}

The PitchBook database was used to screen for a list of SBOs and LBOs to use in the analysis. To start, all SBOs that were of companies domiciled in the United States and that had an EV value for the transaction available were searched for. This search returned 1,630 companies. Upon finding this initial list of companies, the search parameters were expanded to include all transactions of these 1,630 companies (again, where an enterprise value is available. This next search returned 3,069 transactions. These transactions then needed to be sorted and filtered to remove bad data and those that were unnecessary for the analysis.

To perform the analysis relevant to this thesis, only an LBO, the following SBO, and the following exit were needed. Any transaction that did not fit the above criteria was excluded.

Additionally, if for any one company, the LBO, SBO, and exit did not occur in sequential order (i.e., the LBO was transaction "one" in the company's life, and the SBO was transaction "two" in the company's life, etc.), the data for the company was excluded. Lastly, PitchBook provides a deal synopsis for each transaction. These synopses often include a comment as to the 
$\mathrm{EV}$ at the time of the transaction or indicate that the transaction was completed for an "undisclosed amount." If after having read the deal synopsis, there was a discrepancy between the EV mentioned in the deal synopsis and the EV published, the data was excluded. The final list used in this analysis contained 111 transactions (37 companies).

The glaring issue with performing analysis on the U.S. private equity market is that data is scarce. In general, private companies are not required to make public disclosures, so the data available is from either a voluntary press release or because a public company was involved as the buyer or seller in the transaction. As such, the metrics available to analyze are extremely limited. For this reason, the scope of this thesis is limited to analyzing the relationship between LBOs and SBOs concerning EV.

\section{Methodology}

To examine the type of relationship between LBOs and SBOs, the percent change in EV over the life of each transaction was examined. To do this, the absolute percent change in EV from the LBO to the SBO and again for the SBO to the exit was calculated. This absolute change then needed to be annualized so that the data could be directly compared. Each percent change was annualized by subtracting the LBO date from SBO date and the SBO date from the exit date. The result was the number of days of the holding period, so this metric was divided by 365 to put the value into years. Absolute percent changes were annualized by the respective holding period in years.

The above calculation produced two columns of data. One column containing the crosssectional percent change for the LBOs and another for the SBOs. These two columns were analyzed individually and compared to each other. Additionally, a third column of data was created by subtracting the SBO change from the LBO change. This column is a matched sample. A positive value represents an LBO annualized EV change that is greater than the corresponding SBO change and vice versa. A matched sample best allows for an analysis of the relationship between LBOs and SBOs because it shows relative change.

\section{Average Annualized Enterprise Value Change.}

Similar to previous literature, this analysis begins with an assessment of whether LBOs and SBOs generate operational improvements at differing levels. Annualized EV change as a proxy for operational improvement was used. EV is a metric for total asset (company) value; thus, a 
positive change in this metric would indicate operational growth and the opposite would be true if the change were negative. While EV growth is not the sole way PE funds generate target IRRs through their holdings, the metric still can lend to significant insight considering the universality and all-encompassing nature of the metric. The first piece of this analysis involved comparing the means of the annualized change in EV of LBOs to that of SBOs. Additionally, as outlined in the methodology, a matched sample from the above two columns was created by subtracting the SBO change from the LBO change and tested if the mean was significantly different from zero. This first test is not intended to determine whether a significant relationship between LBOs and SBOs exists, but rather to provide additional color concerning findings of previous literature.

Below, Exhibit 1 shows the results of this analysis. Notably, the average change in EV during the LBO holding period and the corresponding variance were much larger than that of the SBO. Additionally, the LBO data showed greater skewness toward the right than did SBOs as displayed by the mean that was just over 5\% larger than the median. As for the holding periods, the data were remarkably similar. The most substantial difference between the holding period of LBOs and SBOs was in the variance, with the variance of SBOs being slightly larger.

To assess whether a company grows at a different rate during its tenure in SBO than it does in LBO, the null hypothesis that the means of the two groups are equal was tested. While this analysis was not a matched sample, it was unique to prior literature in that it was only comparing data where both an LBO and SBO took place on the same company. As can be seen in the table below, the p-value confirmed that based on this data set, the means are not significantly different.

Next, the matched sample of LBO and SBO data was analyzed. When viewing the table, note that the "LBO-SBO" column is not equal to the previous two columns subtracted, but rather the raw SBO data subtracted from the raw LBO data. For the EV change, the table shows that LBOs, on an average and annualized basis, increase in EV $11.5 \%$ more than a corresponding SBO. Similar to the LBO and SBO cross-sectional data sets, the matched sample was also skewed right as signified by the median that was sharply lower than the mean.

While this $11.5 \%$ difference was initially alarming, testing the mean against zero showed no significance in the finding. Though the test did not return significant results, it is unique in that it tests for a relationship between LBOs and SBOs. It is possible, as other studies have done, to analyze a set of LBOs and SBOs against each other that have nothing in common. However, through looking at the matched sample, not only is bias that could result from analyzing buyouts 
of companies completely different from each other eliminated, but the analysis of whether a relationship between LBOs and SBOs exist is made possible. Nonetheless, this particular analysis did not reveal such a relationship.

Exhibit 1: LBO vs. SBO EV Percent Change

\begin{tabular}{|c|c|c|c|c|c|c|}
\hline & \multicolumn{3}{|c|}{ EV Percent Change } & \multicolumn{3}{|c|}{ Holding Period (Years) } \\
\hline Descriptive Statistics & LBO & SBO & LBO-SBO* & LBO & SBO & LBO-SBO* \\
\hline Observations & 37 & 37 & 37 & 37 & 37 & 37 \\
\hline Min & $-14.7 \%$ & $-28.2 \%$ & $-98.6 \%$ & 1.8 & 1.1 & -9.9 \\
\hline Max & $147.0 \%$ & $98.2 \%$ & $148.0 \%$ & 11.6 & 13.6 & 7.5 \\
\hline Variance & $11.2 \%$ & $5.5 \%$ & $21.0 \%$ & 5.0 & 7.5 & 13.7 \\
\hline Mean & $24.9 \%$ & $13.4 \%$ & $11.5 \%$ & 5.5 & 5.0 & 0.5 \\
\hline Median & $19.2 \%$ & $9.8 \%$ & $5.5 \%$ & 4.8 & 4.3 & 1.0 \\
\hline Standard Deviation & $33.5 \%$ & $23.5 \%$ & $45.8 \%$ & 2.2 & 2.7 & 3.7 \\
\hline Hypothesis Tests & t-Stat & P-Value & & & & \\
\hline LBO vs. SBO & 1.714 & .0913 & & & & \\
\hline Matched Sample vs. Zero & 1.531 & .1346 & & & & \\
\hline
\end{tabular}

*Matched Sample

\section{The Holding Period/Enterprise Value Change Relationship}

To further discover if any relationships exists between LBOs and SBOs, whether the holding period was correlated to annualized enterprise value change in a significant way was analyzed. This test was run for all three groups of data (LBO, SBO, and the matched sample). Both Wang and Degeorge, Martin, and Phalippou found that SBOs were more likely to underperform when the exit occurred near the end of a fund's investment horizon. This finding is expanded by showing to what extent lengthening the holding period can damage EV growth.

Both the LBO and SBO EV change showed a significant negative relationship to the holding period. The results of this regression can be found in Exhibit 2, below. Additionally, graphs depicting the relationship can be found in Exhibits 3 and 4. The results of both the LBO and SBO tests were consistent with each other: as the holding period lengthens, the likelihood that EV growth decreases strengthens. That being said, the relationship was slightly stronger and had a more modest slope for SBOs than for LBOs. For LBOs and SBOs, as the holding period 
lengthens by one year, the annualized EV change is predicted to decrease by $5.69 \%$ and $3.65 \%$, respectively.

This phenomenon could be explained by the fact that PE fund managers require many years to implement their planned value-creating strategies with their portfolio companies. As such, very few funds will choose to sell a portfolio company in the first few years of ownership. The exception is when a PE fund receives an unsolicited offer that is too good to refuse and chooses to sell the company shortly after buying it because the profit is so high. Supporting this idea is that all the extremely positive EV change values occur before a holding period of five years is reached, as can be seen in the LBO graph.

Having tested for a relationship individually, whether the matched sample showed a similar relationship was tested. The results of the matched-sample are more difficult to comprehend at a glance due to the arithmetic in creating the matched-sample. Essentially, as the LBO holding period grows relative to the SBO holding period, the SBO EV change grows positively in relation to the LBO EV change. Said another way, the more an LBO holding period is longer than the SBO holding period, the more likely the SBO annualized EV change will be greater than the LBO annualized EV change. This finding is in concurrence with the findings in the prior two regressions and confirms that a relationship between LBOs and SBOs regarding holding period does exist.

This finding should be taken into account in tandem with the earlier finding that exits that occur early on in the investment tend to have an extremely high annualized change in EV. For a company to be re-priced in that short of a period, there must be an inefficiency present; either the initial buyer paid too little or the second buyer paid too much. According to these results, it appears the second buyer is often paying too much and thus makes it difficult for themselves to turnaround and produce an equally grand change in company value. If EV growth is a goal, PE managers should take this into account when tempted to purchase a holding from another fund shortly after it had just been acquired. 
Exhibit 2: Enterprise Value Change and Holding Period Regression Results

\begin{tabular}{|c|c|c|c|c|c|c|c|c|}
\hline \multicolumn{9}{|c|}{ Regression Results } \\
\hline $\begin{array}{c}\text { Independent } \\
\text { Variable }\end{array}$ & $\begin{array}{c}\text { Dependent } \\
\text { Variable }\end{array}$ & $\mathbf{r}^{2}$ & Intercept & Slope & t-Stat & $\begin{array}{c}\mathrm{p}- \\
\text { Value }\end{array}$ & $\begin{array}{l}95 \% \\
\text { Lower }\end{array}$ & $\begin{array}{l}95 \% \\
\text { Upper }\end{array}$ \\
\hline LBO Holding & LBO EV & & & 5.69 & . & & & \\
\hline Period & Change & 0.144 & $56.13 \%$ & $\begin{array}{c}\% \\
-\end{array}$ & 2.424 & .0207 & $-10.45 \%$ & $-0.92 \%$ \\
\hline SBO Holding & SBO EV & & & 3.65 & - & & & \\
\hline Period & Change & 0.183 & $31.67 \%$ & $\begin{array}{r}\% \\
- \\
4.93\end{array}$ & 2.798 & .0083 & $-6.30 \%$ & $-1.00 \%$ \\
\hline LBO - SBO (HP) & LBO - SBO (EV) & 0.158 & $13.89 \%$ & $\%$ & 2.563 & .0148 & $-8.83 \%$ & $-1.02 \%$ \\
\hline
\end{tabular}

Exhibit 3: LBO Annualized EV Change vs. LBO Holding Period

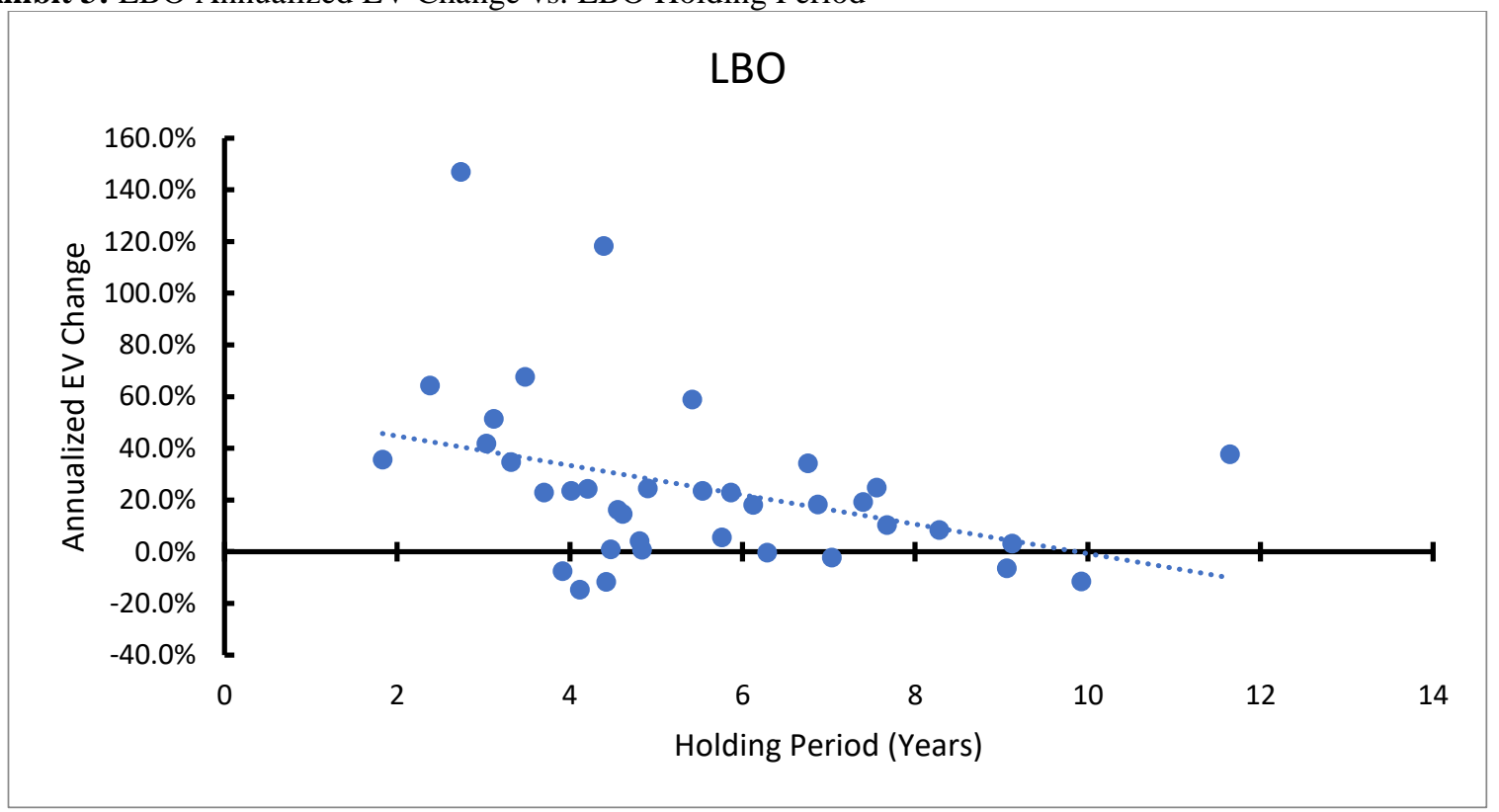


Exhibit 4: SBO Annualized EV Change vs. SBO Holding Period

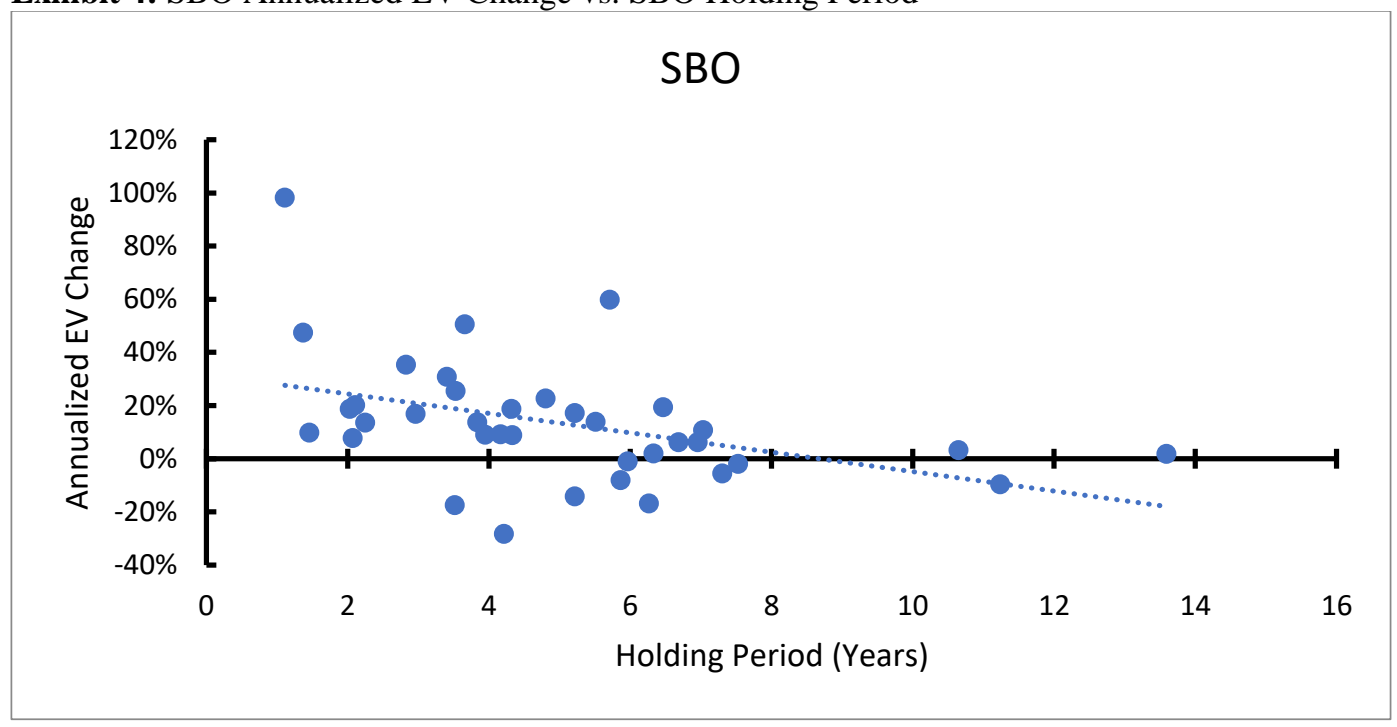

Exhibit 5: LBO - SBO Annualized EV Change. vs. LBO - SBO Holding Period

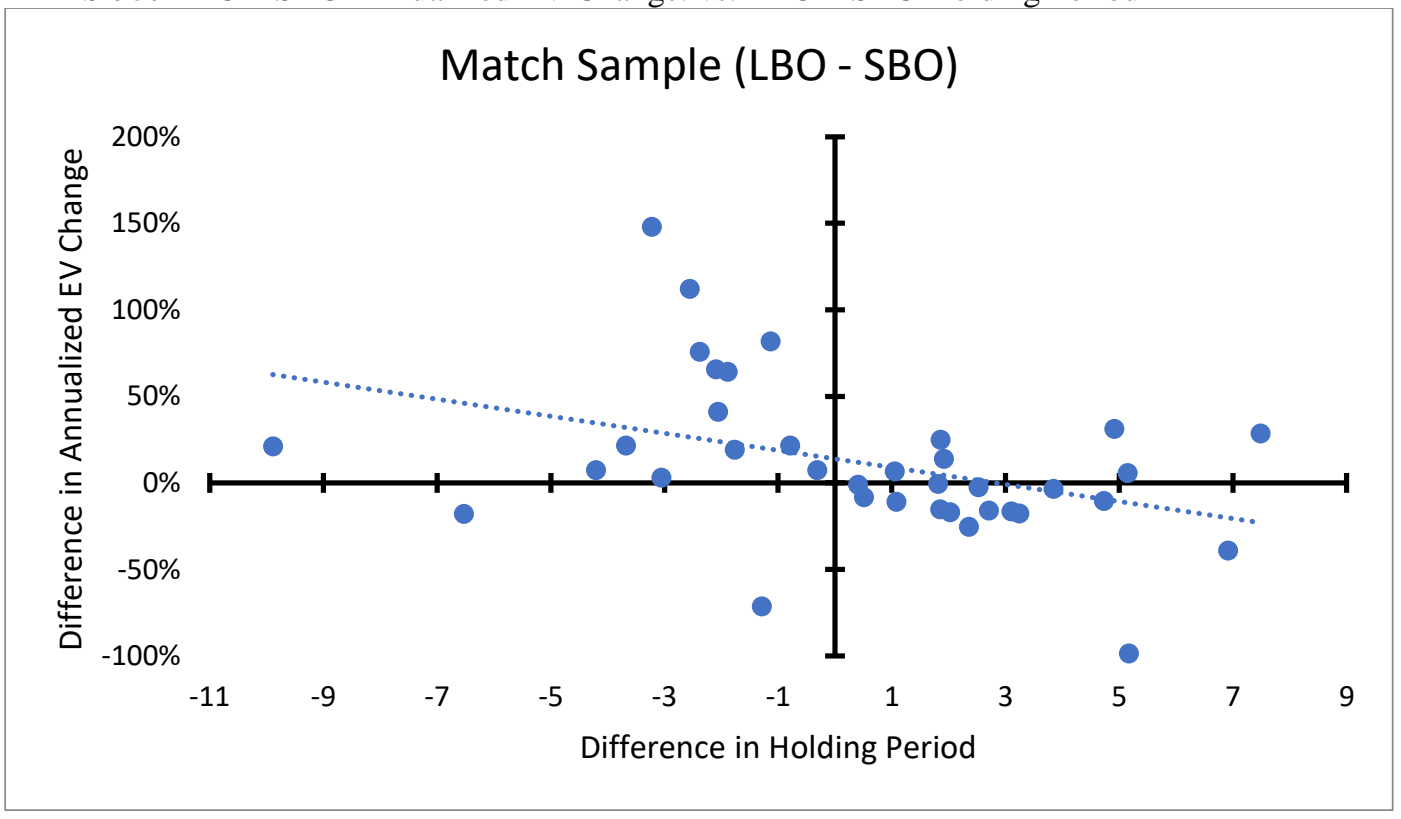

\section{Direct Relationship of EV Change of LBOs and SBOs}

The final test used to analyze the EV relationship between LBOs and SBOs was a direct regression of the change in EV for both groups. Undeniably, this test was particularly openended and had the results been significant, it would not provide much detail as to the reasons for the results. Nonetheless, considering the topic, this was the bluntest test that could be performed. Before running the test, the assumption was, EV change between LBOs and SBOs should have a negative relationship. The principal reason being that for an SBO to see outsized enterprise value 
growth, the SBO must be purchased at a favorable price, or the company must see extraordinary and unexpected growth over the holding period. It is much easier to do well with an investment when the purchase price of that investment was low. Consequently, SBOs and LBOs should be inversely related concerning EV change.

As shown in the r-squared in Exhibits 6, the correlation of this regression was very low, and the test did not return a significant result. Looking at the graph in Exhibit 7, the slope of the line of best fit was seemingly drawn down by two outliers where the LBO EV change was extremely positive, and the SBO EV change was less than notable. A slight negative relationship was present; however, it was not conclusive enough to warrant any clear suppositions.

Exhibit 6: LBO Annualized EV Change vs. SBO Annualized EV Change - Table

\begin{tabular}{|c|c|c|c|c|c|c|c|c|}
\hline & & & Regression & esults & & & & \\
\hline & & & & & & & Confiden & nterval \\
\hline $\begin{array}{l}\text { Independent } \\
\text { Variable }\end{array}$ & $\begin{array}{c}\text { Dependent } \\
\text { Variable }\end{array}$ & $r^{2}$ & Intercept & Slope* & t-Stat & p-Value & $\begin{array}{l}95 \% \\
\text { Lower }\end{array}$ & $\begin{array}{c}95 \% \\
\text { Upper }\end{array}$ \\
\hline LBO \% EV & SBO \% EV & & & & - & & & \\
\hline Change & Change & 0.073 & $18.08 \%$ & $-1.89 \%$ & 1.662 & 0.105 & $-42.05 \%$ & $4.19 \%$ \\
\hline
\end{tabular}

*for every percent change in LBO

Exhibit 7: LBO Annualized EV Change vs. SBO Annualized EV Change - Graph

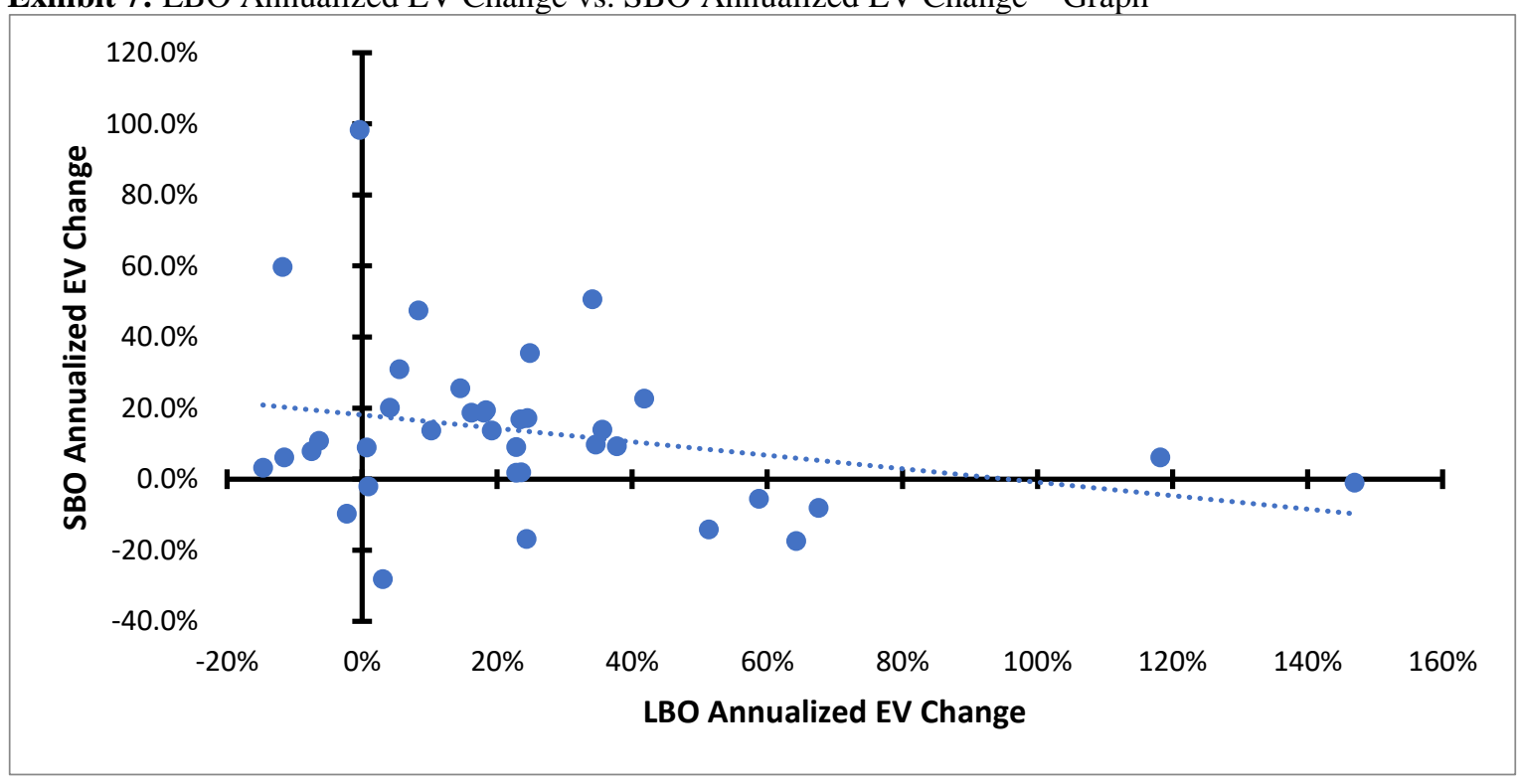

\section{Conclusion}

The data analyzed above provides for some relationship between LBOs and SBOs, though that relationship was embedded in additional factors (i.e., holding period). PE funds should be wary of SBOs where the previous owner held the company for an ultra-short period as the 
likelihood of producing an equally disproportionate EV change are low. However, overall, SBOs do not have a lower annualized EV change when compared to the preceding LBOs. Thus, PE funds should only be wary of SBOs under certain circumstances. In general, PE funds should feel comfortable investing in SBOs, but should also understand that some factors could limit their likelihood of success, one of them being holding period.

\section{References}

Achleitner, A.-K., \& Figge, C. (2014). Private Equity Lemons? Evidence on Value Creation in Secondary Buyouts. European Financial Management, 20(2), 406-433. https://doi.org/10.1111/j.1468036X.2012.00644.X

Degeorge, F., Martin, J., \& Phalippou, L. (2016). On secondary buyouts. Journal of Financial Economics, 120(1), 124-145. https://doi.org/10.1016/j.jfineco.2015.08.007

Wang, Y. (2012). Secondary buyouts: Why buy and at what price? Journal of Corporate Finance, 18(5), 1306-1325. https://doi.org/10.1016/j.jcorpfin.2012.09.002

Wilder, J. (2018, August 24). How secondary buyouts became ubiquitous: SBOs as an exit and deal sourcing strategy. [Blog]

Kitzmann, J., \& Schiereck, D. (2009). A note on secondary buyouts-creating value or recycling capital. iBusiness, 1(2). Retrieved from https://m.scirp.org/papers/1054.

Plagborg-Møller, E., \& Holm, M. (2017). IPO or SBO?: The Increasing Importance of Operational Performance for Private Equity Exits Following the Global Financial Crisis of 2007-08. Journal of Applied Corporate Finance, 29(1), 115-129. Doi: 10.1111/jacf.12225.

Bonini, S. (2015). Secondary Buyouts: Operating Performance and Investment Determinants. Financial Management, 44(2), 431-470. http://dx.doi.org/10.2139/ssrn.1571249 